\title{
Review Article \\ Function and Regulation of the Plant COPT Family of High-Affinity Copper Transport Proteins
}

\author{
Sergi Puig \\ Departamento de Biotecnología, Instituto de Agroquímica y Tecnología de Alimentos (IATA), Consejo Superior de Investigaciones \\ Científicas (CSIC), Avenida Agustín Escardino 7, Paterna, 46980 Valencia, Spain
}

Correspondence should be addressed to Sergi Puig; spuig@iata.csic.es

Received 1 April 2014; Accepted 29 May 2014; Published 21 July 2014

Academic Editor: Tomotsugu Koyama

Copyright (C) 2014 Sergi Puig. This is an open access article distributed under the Creative Commons Attribution License, which permits unrestricted use, distribution, and reproduction in any medium, provided the original work is properly cited.

Copper $(\mathrm{Cu})$ is an essential micronutrient for all eukaryotes because it participates as a redox active cofactor in multiple biological processes, including mitochondrial respiration, photosynthesis, oxidative stress protection, and iron (Fe) transport. In eukaryotic cells, $\mathrm{Cu}$ transport toward the cytoplasm is mediated by the conserved CTR/COPT family of high-affinity Cu transport proteins. This outlook paper reviews the contribution of our research group to the characterization of the function played by the Arabidopsis thaliana COPT1-6 family of proteins in plant $\mathrm{Cu}$ homeostasis. Our studies indicate that the different tissue specificity, Curegulated expression, and subcellular localization dictate COPT-specialized contribution to plant $\mathrm{Cu}$ transport and distribution. By characterizing lack-of-function Arabidopsis mutant lines, we conclude that COPT1 mediates root Cu acquisition, COPT6 facilitates shoot $\mathrm{Cu}$ distribution, and COPT5 mobilizes $\mathrm{Cu}$ from storage organelles. Furthermore, our work with copt2 mutant and COPToverexpressing plants has also uncovered $\mathrm{Cu}$ connections with Fe homeostasis and the circadian clock, respectively. Future studies on the interaction between COPT transporters and other components of the Cu homeostasis network will improve our knowledge of plant $\mathrm{Cu}$ acquisition, distribution, regulation, and utilization by $\mathrm{Cu}$-proteins.

\section{Introduction}

Copper $(\mathrm{Cu})$ functions as a redox active cofactor in a wide variety of plant proteins including plastocyanin, cytochrome $c$ oxidase, $\mathrm{Cu} / \mathrm{Zn}$-superoxide dismutase ( $\mathrm{Cu} / \mathrm{Zn}-\mathrm{SOD})$, ethylene receptors, laccases, ascorbate and amine oxidases, plantacyanin, and polyphenol oxidases. Consequently, $\mathrm{Cu}$ is essential for fundamental biological processes in plants including photosynthesis, mitochondrial respiration, oxidative stress protection, cell wall metabolism, ethylene perception, response to pathogens, and molybdenum cofactor biosynthesis [1-3]. The optimal endogenous $\mathrm{Cu}$ levels in plants can substantially range depending on the species and its environmental availability. Adequate $\mathrm{Cu}$ levels in vegetative tissues are around $6 \mu \mathrm{g} / \mathrm{g}$ dry weight, with levels below $5 \mu \mathrm{g} / \mathrm{g}$ leading to deficiency symptoms [4]. Cu deficiency defects in plants include a general reduced growth rate, chlorosis, especially in young leaves, curling of leaf margins, damage at the apical meristem, defects in cell wall formation, and lignification, which causes insufficient water transport, defective pollen development and viability, limited fruit formation, and diminished seed production and viability [4]. Plant $\mathrm{Cu}$ availability also depends on soil composition, with organic soils being more likely to be $\mathrm{Cu}$-deficient due to higher Cu-binding capacity [4]. In addition to the variable availability of $\mathrm{Cu}$ in the environment, plant $\mathrm{Cu}$ requirements also change daily given its participation in photosynthesis, during the development of green and reproductive tissues, and in response to other environmental cues.

Higher plants have developed sophisticated mechanisms to efficiently acquire and utilize $\mathrm{Cu}$, especially when it is scarce. Cells from the model plant Arabidopsis thaliana respond to $\mathrm{Cu}$ deficiency through a dual mechanism that consists in increasing $\mathrm{Cu}$ acquisition and optimizing its utilization (reviewed by $[1,2,5-7]$ ). In response to $\mathrm{Cu}$ limitation, Arabidopsis master $\mathrm{Cu}$ homeostasis regulator SPL7 (SQUAMOSA promoter-binding protein-like 7), similar to Chlamydomonas reinhardtii Crrl transcription factor [8], activates the expression of multiple genes that contain within their promoter repetitive $\mathrm{Cu}$-responsive elements (CuREs) 
with a GTAC motif as the essential core sequence [911]. Upon $\mathrm{Cu}$ limitation, SPL7 activates the expression of $\mathrm{Cu}^{2+}$-reductases (FRO4 and FRO5) and high-affinity $\mathrm{Cu}$ transporters (COPT1, COPT2, and COPT6) at the plasma membrane that mediate $\mathrm{Cu}^{+}$transport to the cytoplasm $[9,10,12,13]$ (see below). In addition to $\mathrm{Cu}$ acquisition, SPL7 triggers the expression of various microRNAs, denoted $\mathrm{Cu}$-microRNAs, which promote the degradation of the transcripts encoding for dispensable $\mathrm{Cu}$-utilizing proteins, including cytosolic $\mathrm{Cu} / \mathrm{Zn}$-SOD (CSD1), chloroplast stroma $\mathrm{Cu} / \mathrm{Zn}-\mathrm{SOD}$ (CSD2), several laccases, and plantacyanin [9, 14-16]. To compensate for reduced $\mathrm{Cu} / \mathrm{Zn}$-SOD activity in chloroplasts, the SPL7 transcription factor also enhances the expression of plastid-localized Fe-SOD (FSDI) $[9,17,18]$. After entering the cytoplasm, $\mathrm{Cu}$ is delivered to specific $\mathrm{Cu}-$ containing proteins by specialized $\mathrm{Cu}$ chaperones. The major pathway for $\mathrm{Cu}$ supply to $\mathrm{Cu} / \mathrm{Zn}$-SOD utilizes the CCS1 $\mathrm{Cu}$ chaperone [19-22], whereas ATX-like metallochaperones mediate $\mathrm{Cu}$ delivery to the $\mathrm{Cu}$-proteins located on the secretory pathway or in plastids by interacting and transferring the cofactor to Cu-transporting P-type ATPases [23, 24]. RAN1 P-type ATPase pumps cytosolic $\mathrm{Cu}$ toward the secretory pathway for incorporation into $\mathrm{Cu}$-proteins such as the ethylene receptor $[25,26]$. PAAl ATPase, which is located in the inner chloroplast envelope, mediates $\mathrm{Cu}$ transport from the cytoplasm to plastid stroma, and the thylakoid-located PAA2 facilitates final $\mathrm{Cu}$ delivery to plastocyanin into the thylakoid lumen $[17,27,28]$. Therefore upon $\mathrm{Cu}$ scarcity, cofactor delivery to multiple nonessential or replaceable $\mathrm{Cu}$ consuming enzymes is reduced to prioritize the utilization of $\mathrm{Cu}$ in essential $\mathrm{Cu}$-dependent processes such as photosynthetic electron transport $[28,29]$.

Numerous studies on yeasts, mammals, insects, algae, and plants have revealed that eukaryotes utilize the conserved CTR/COPT family of proteins to facilitate highaffinity $\left(K_{m}=1-5 \mu \mathrm{M}\right)$ cellular $\mathrm{Cu}$ acquisition at the plasma membrane and $\mathrm{Cu}$ mobilization from intracellular storage organelles, when $\mathrm{Cu}$ bioavailability decreases [30-35]. CTR/COPT proteins are highly specific for $\mathrm{Cu}^{+}$transport (and the isoelectric $\mathrm{Ag}^{+}$), but not for $\mathrm{Cu}^{2+}[13,36,37]$. Consequently, they function in coordination with membrane metalloreductases that catalyze $\mathrm{Cu}^{2+}$ reduction to $\mathrm{Cu}^{+}$before transport $[38,39]$. The conserved features in CTR/COPT proteins include three transmembrane domains (TMDs), an amino-terminal region rich in methionine and/or histidine residues and an essential $\mathrm{Mx}_{3} \mathrm{Mx}_{12} \mathrm{Gx}_{3} \mathrm{G}$ signature motif embedded within TMD2 and TMD3 (Figure 1(a)). Genetic, biochemical, and structural data suggest that, in the first steps of $\mathrm{Cu}$ transport, extracellular methionine/histidine-rich motifs recruit $\mathrm{Cu}^{+}$to the entrance of the pore and facilitate its subsequent translocation to a set of stacked methionine triads that provide a central $\mathrm{Cu}^{+}$-driving path from the external domain of the complex (Figure 1(b)). After passing through the pore, $\mathrm{Cu}^{+}$would bind to the carboxy-terminal cysteine/histidine motifs facing the cytoplasm, which modulate $\mathrm{Cu}^{+}$-transport activity and delivery to membraneassociated metallochaperones for targeted distribution [4045]. This outlook paper focuses on our contribution to characterizing the function and regulation of the different members of the conserved CTR/COPT family of high-affinity $\mathrm{Cu}$ transporters in the model plant Arabidopsis thaliana.

\section{Contribution of Studies in Yeast to the Identification and Initial Characterization of Plant COPT High- Affinity Copper Transporters}

Saccharomyces cerevisiae ctr $1 \Delta$ ctr $3 \Delta$ mutants lack highaffinity $\mathrm{Cu}$ acquisition systems at the plasma membrane and, consequently, display defects in $\mathrm{Cu}$ delivery to $\mathrm{Cu}$ proteins, including cytochrome $c$ oxidase at the mitochondrial respiratory chain and multicopper ferroxidase Fet3 in the plasma membrane high-affinity iron (Fe) uptake system. Thus, yeast $c t r 1 \Delta c t r 3 \Delta$ mutants display growth defects under both nonfermentable carbon sources (respiratory conditions) and Fe limitation. By functionally complementing the respiratory and low Fe defects exhibited by yeast ctr $1 \Delta c t r 3 \Delta$ mutants, we completed the identification of the COPT1-6 family of high-affinity $\mathrm{Cu}$ transporters in A. thaliana $[6,12$, 13, 46-48]. We observed that, with the exception of COPT4, the ectopic expression of all the Arabidopsis COPT family members expressed in yeast $\mathrm{Cu}$ transport mutants stimulates $\mathrm{Cu}$ uptake and accumulation [12, 13, 49]. Regarding yeast growth complementation, COPT1, COPT2, and COPT6 fully rescued the $c t r 1 \Delta c t r 3 \Delta$ defect under nonfermentable and low Fe conditions, whereas the COPT3 and COPT5 effect was only partial $[6,12,13,48]$. We observed that COPT4 expression, which does not possess the key methionine residues essential for $\mathrm{Cu}$ transport, including the $\mathrm{MX}_{3} \mathrm{M}$ motif, proves toxic to yeast cells [13]. Thus, the COPT4 potential function, if any, in plant $\mathrm{Cu}$ homeostasis remains to be elucidated. All together, these data suggest that, similarly to the CTR/COPT proteins in other organisms, Arabidopsis COPT family members are CTR-type proteins that utilize conserved methionine motifs for $\mathrm{Cu}$ transport.

\section{Subcellular Localization and Copper Regulation of COPT Transporters in Arabidopsis}

Budding yeast cells possess two $\mathrm{Cu}$ transport proteins at the plasma membrane (Ctr1 and Ctr3), whose expression is highly induced upon Cu deficiency in order to facilitate highaffinity $\mathrm{Cu}$ acquisition, and an intracellular $\mathrm{Cu}$ transporter (Ctr2), which mobilizes $\mathrm{Cu}$ from the vacuolar storage compartment when $\mathrm{Cu}$ is extremely scarce [50]. Recent studies by our and other research groups have shown that a similar division of functions occurs in Arabidopsis COPT proteins. Whereas fusions of COPT1, COPT2, and COPT6 to the green fluorescent protein (GFP) localize at the plasma membrane in plant cells, COPT5 is intracellularly localized [12, 4749, 51-53] (Figure 2(a)). As indicated above, the $\mathrm{Cu}$-regulated transcription factor SPL7 specifically activates the expression of COPT1, COPT2, and COPT6 genes in response to $\mathrm{Cu}$ deficiency, whereas no $\mathrm{Cu}$ regulation has been observed for COPT3 and COPT5 genes $[9,12,13,47]$ (Figure 2(b)). 


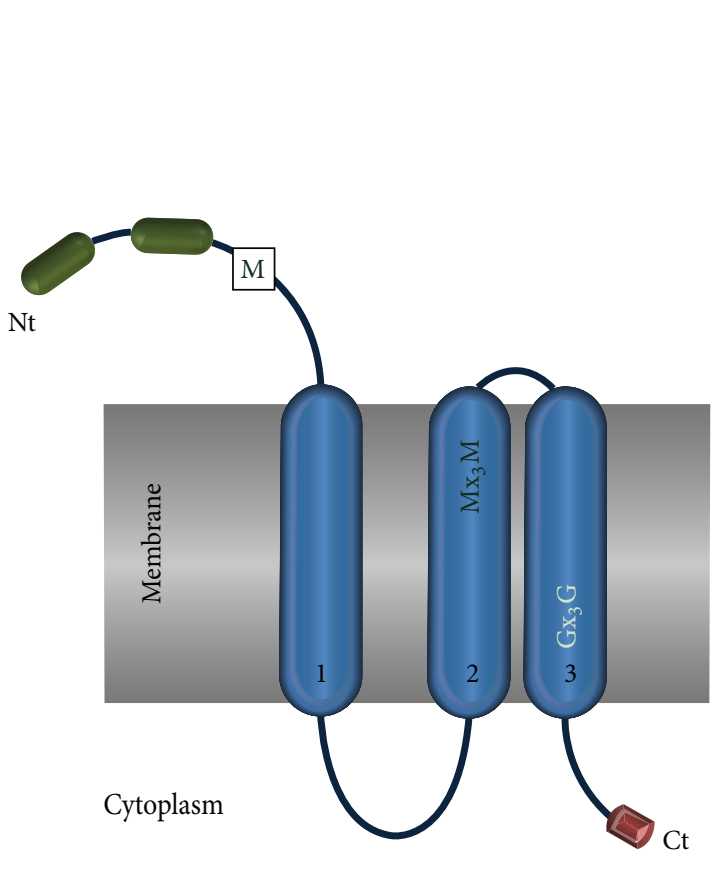

(a)

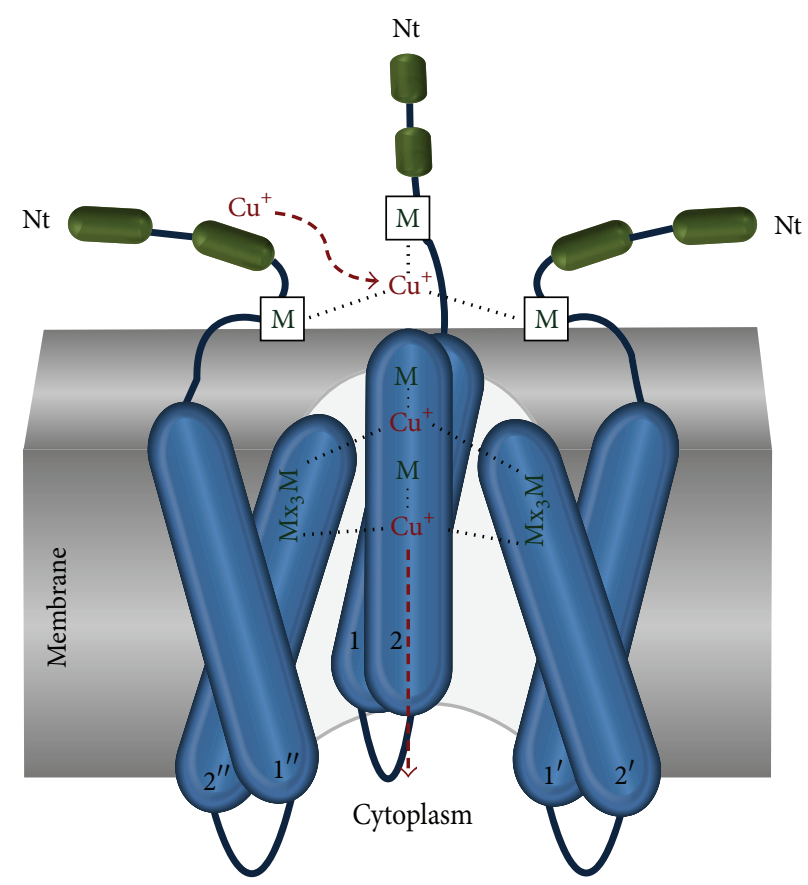

(b)

FIgURE 1: Conserved features in CTR/COPT family proteins. (a) CTR/COPT topology and conserved domains and motifs. The three TMDs are shown in blue. Green boxes represent extracellular methionine/histidine-rich motifs and red boxes indicate cytoplasmic cysteine/histidine motifs. (b) Representation of the assembly of CTR/COPT trimers in the membrane. The model highlights the role of methionines in the mechanism of copper transport. Only TMDs 1 and 2 have been represented for simplicity.

\section{COPT1 Protein Constitutes the Major Arabidopsis Root Copper Acquisition System}

Arabidopsis COPT1 was the first plant COPT family member to be identified $[13,46,51,54]$. By fusing the COPT1 promoter region to the uidA gene, which encodes $\beta$-glucuronidase (GUS), we determined that COPT1 is expressed mostly in the root apex, cotyledons, stomata, trichomes, pollen grains, and embryos [54] (Figures 2(c) and 2(d)). Consistently with its tissue and $\mathrm{Cu}$-regulated expression, we determined that seedlings with low COPT1 transcript levels display a 50\% decrease in root $\mathrm{Cu}$ acquisition, and consequently COPT1defective plants displayed growth and pollen development defects when $\mathrm{Cu}$ availability was limited [54] (Figure 2(e)). It is noteworthy that we reverted these defects by $\mathrm{Cu}$ feeding, indicating that the $\mathrm{Cu}$-transporting capacity of the COPT1 protein is crucial for soil $\mathrm{Cu}$ acquisition and pollen development when environmental $\mathrm{Cu}$ is scarce. By ${ }^{64} \mathrm{Cu}$ uptake and metal competition experiments in yeast cells, we established that COPT1 is highly specific for $\mathrm{Cu}^{+}$since its transport is only inhibited considerably by addition of excess $\mathrm{Ag}^{+}$, whereas only a minor effect is observed for other divalent metals [13]. Our results implied that, as previously described in other eukaryotic organisms, Arabidopsis root $\mathrm{Cu}$ uptake would also require cell surface $\mathrm{Cu}^{2+}$-reductases to function under $\mathrm{Cu}$-deficient conditions. A recent study by Kramer's group has shown that the mRNA levels of FRO4 and $F R O 5 \mathrm{Fe}^{3+}$-reductases strongly increase in an SPL7dependent manner in response to $\mathrm{Cu}$ deficiency [10]. More importantly, under low $\mathrm{Cu}$ conditions, plants that are defective in SPL7, FRO4, or FRO5 expression display markedly diminished root $\mathrm{Cu}^{2+}$-reductase activity, which leads to a drastic drop in $\mathrm{Cu}$ uptake at the root tips [10]. All these results strongly suggest that $\mathrm{Cu}^{2+}$ is first reduced by $\mathrm{Cu}^{2+}$-reductases FRO4 and FRO5, and then $\mathrm{Cu}^{+}$is imported into plant roots by the COPT1 $\mathrm{Cu}^{+}$transporter. Little is known about the proteins responsible for the remaining Arabidopsis root $\mathrm{Cu}$ uptake activity. We postulate that Arabidopsis COPT2, which is also highly expressed in roots, may constitute a secondary pathway for root $\mathrm{Cu}$ incorporation [47] (see below). In fact, we have observed that COPT1-defective plants upregulate COPT2 transcript levels, which can potentially relieve its defects in root $\mathrm{Cu}$ transport partially [54]. Since the $\mathrm{Cu}$ accumulation defect of the copt 2 mutant plants is not marked [47] (see below), we seek to combine the effect of both COPT1 and COPT2 defects by analyzing $\mathrm{Cu}$ uptake in coptlcopt2 double mutants. The sharp drop in $\mathrm{Cu}$ uptake at the root tip that the FRO4- and FRO5-defective plants exhibit does not mean that we can rule out that plant $\mathrm{Cu}$ acquisition can eventually occur at other places in the root by different families of metal transporters. For instance, Arabidopsis ZIP2 and ZIP4 transporters improve the growth defect in nonfermentable carbon sources of yeast cells that are defective in the high-affinity $\mathrm{Cu}$ uptake system at the plasma membrane, and their mRNA levels increase upon $\mathrm{Cu}$ limitation [55]. 


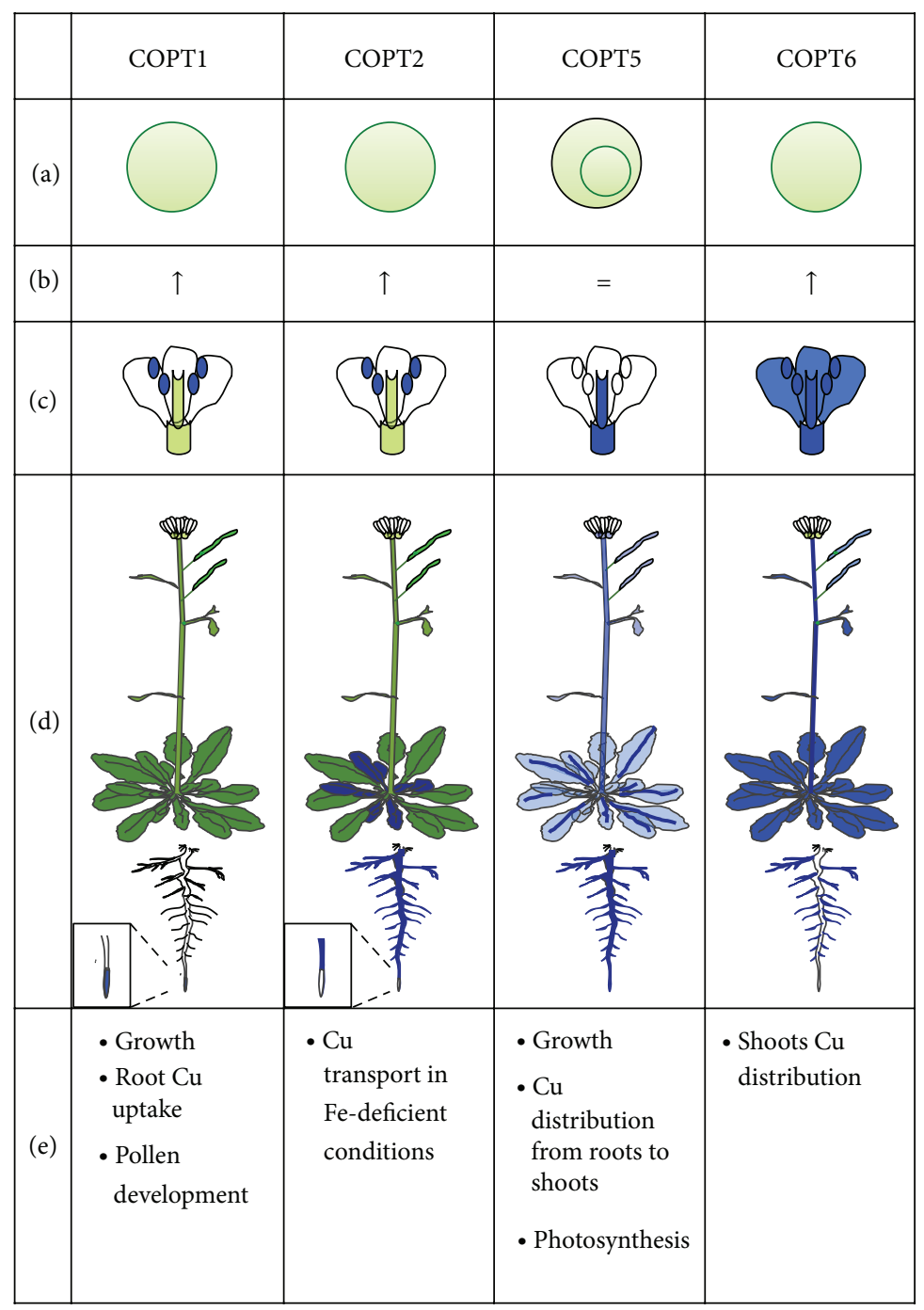

FIgURE 2: Characterization of Arabidopsis COPT family members. (a) Subcellular localization in Arabidopsis protoplasts. COPT-GFP protein localization is indicated in green. (b) Transcript regulation in response to copper deficiency. (c) Expression pattern in flowers. (d) Expression pattern in roots and shoots. (e) Parameters affected in copt mutant lines upon copper scarcity. COPT3 and COPT4 have not been included due to the small amount of data currently available.

Comparing root $\mathrm{Cu}$ uptake and other phenotypes of single mutants to plants that are simultaneously defective in various $\mathrm{Cu}$-regulated transporters will help to decipher their relative contribution to plant $\mathrm{Cu}$ acquisition.

\section{Arabidopsis COPT2 Lies at the Intersection between Copper and Iron Homeostases}

Among the COPT genes, COPT2 mRNA displays the most marked SPL7-dependent increase in response to $\mathrm{Cu}$ deficiency $[9,13,47,56]$. By using transgenic Arabidopsis lines that express a fusion between COPT2 promoter and GUS reporter, we have determined that, under low $\mathrm{Cu}$ conditions, COPT2 is expressed mainly in roots, the vasculature of cotyledons and young leaves, apical meristems, and trichomes $[47,49]$ (Figure 2(d)). In reproductive tissues, COPT2 concentrates mostly in stigma, anthers, and pollen [47, 49] (Figure 2(c)). Similar results were obtained by Vatamaniuk's group [47, 49]. Interestingly, our results show that, whereas COPT1 and COPT2 transcript expression patterns in shoots are similar, a notable difference is shown in roots. We observe that $C O P T 1$ is present exclusively in primary and secondary root tips, whereas COPT2 is absent from elongation and meristemic zones but is highly expressed in the root differentiation zone, lateral roots, and hair roots $[13,47]$ (Figure 2(b)). Despite the COPT2 expression in roots, its contribution to soil $\mathrm{Cu}$ acquisition seems minimum as compared to COPT1 $[13,47]$.

COPT2 transcript levels also rise in response to $\mathrm{Fe}$ deficiency $[57,58]$, although our results point that its tissue expression pattern differs from that observed under $\mathrm{Cu}$ deficient conditions, and concentrates mostly in cotyledons [47]. Consistently with this predominant aerial expression, root transcription factor FIT1 is only partially responsible for COPT2 induction by Fe limitation [57]. A potential explanation for COPT2 mRNA induction by low Fe could 
be increasing cofactor availability for $\mathrm{Cu}$-dependent enzymes such as $\mathrm{Cu} / \mathrm{Zn}$-SOD, which replaces Fe-SOD when Fe is scarce [17]. In fact, we have observed that wild-type, but not copt2, mutant plants increase $\mathrm{Cu}$ content in response to Fe deprivation $[47,58,59]$. Furthermore, ccs1 plants, which are defective in $\mathrm{Cu}$ delivery to $\mathrm{Cu} / \mathrm{Zn}-\mathrm{SOD}$, display increased oxidative damage under Fe deficiency, suggesting a role for $\mathrm{Cu}$ in oxidative stress protection [58]. These observations indicate that Arabidopsis plants optimize Fe utilization by decreasing its use in Cu-replaceable functions and by prioritizing essential $\mathrm{Fe}$-dependent processes.

Interestingly, we observed that simultaneous $\mathrm{Cu}$ and Fe deprivation leads to a further increased COPT2 mRNA expression, especially in roots $[47,58]$. We did not find phenotypic differences between wild-type and copt2-defective plants under normal or $\mathrm{Cu}$ scarce conditions, whereas copt 2 mutants exhibit better maintenance of the photosynthetic apparatus than wild-type seedlings under simultaneous $\mathrm{Cu}$ and Fe deficiencies [47]. Specifically, Arabidopsis copt2 seedlings display reduced leaf chlorosis, increased chlorophyll, and higher plastocyanin content under simultaneous low $\mathrm{Cu}$ and $\mathrm{Fe}$, which leads to improved plant growth and seed production [47]. Although we have not fully elucidated the molecular basis underlying the copt2 mutant phenotype with both $\mathrm{Fe}$ and $\mathrm{Cu}$ defects, global gene expression analyses indicate a general effect of COPT2-mediated $\mathrm{Cu}$ transport in phosphate starvation signaling, which is highly connected to Fe homeostasis $[47,60]$.

As previously mentioned, high-affinity Fe uptake at the plasma membrane depends in S. cerevisiae on Fet3 ferroxidase, which uses $\mathrm{Cu}$ as an indispensable cofactor for its activity. Therefore, $\mathrm{Cu}$ deficiency leads to impaired $\mathrm{Fe}$ transport in yeast, and consequently to multiple Ferelated symptoms [61]. Likewise in green alga C. reinhardtii, multicopper ferroxidase FOX1 participates in cellular $\mathrm{Fe}$ acquisition [62]. In humans, inorganic Fe acquisition in the intestine is mediated by divalent metal transport denoted DMT1, which is independent of $\mathrm{Cu}$, but $\mathrm{Fe}$ distribution depends directly on multicopper ferroxidases ceruloplasmin and hephaestin (reviewed in [63]). Root Fe acquisition in Arabidopsis plants mostly depends on IRT1, a member of the ZIP divalent metal transporter family that does not require $\mathrm{Cu}$ for its transport activity [64-67]. Notwithstanding, in addition to ours, various studies have also linked $\mathrm{Cu}$ and Fe homeostases in plants. Severe $\mathrm{Cu}$ deficiency, achieved by growing Arabidopsis seedlings defective in SPL7 transcription factor (spl7-2 mutants) under low $\mathrm{Cu}$ conditions, leads to reduced root-to-shoot Fe translocation that activates various Fe deficiency responses, including an increased root surface $\mathrm{Fe}^{3+}$-reductase activity and higher IRT1 expression levels, and diminished shoot Fe-dependent enzyme catalase and lower aerial ferritin levels [10]. Interestingly, spl7-2 mutant plants also display severely reduced root ferroxidase activity when cultivated under $\mathrm{Cu}$ deficiency, suggesting that a multicopper ferroxidase may participate in root-to-shoot Fe translocation [10]. Furthermore, the spl7-2 phenotypic defects under $\mathrm{Cu}-$ deficient conditions, including chlorosis, are partially rescued by Fe supplementation [10]. We postulate that COPT2 could also be responsible for $\mathrm{Cu}$ delivery to multicopper oxidases LPR1 and LPR2, which are involved in the root growth responses to low phosphate [68]. In agreement with this hypothesis, we observe that the copt 2 mutants display larger roots than wild-type seedlings and phosphate starvation diminishes COPT2 expression levels [47, 69]. Determining the function of plant $\mathrm{Cu}$-proteins, including multicopper oxidases like ascorbate oxidases and laccases, will help our understanding of the connections of $\mathrm{Cu}$ to $\mathrm{Fe}$ homeostasis and phosphate metabolism.

\section{The COPT6 Protein Facilitates $\mathrm{Cu}$ Distribution in Aerial Tissues}

Although it was not initially annotated in the Arabidopsis genome, our analyses uncovered that At2g26975, denoted COPT6, was a novel member of the COPT family of highaffinity $\mathrm{Cu}$ transporters [6]. Unlike COPT1 and COPT2, our studies and those by Vatamaniuk's group indicate that COPT6 is expressed mostly in shoots, especially in the vasculature of stems and leaves $[12,47]$ (Figure 2(d)). COPT6 can also be found in cotyledons, meristems, trichomes, and stomata [12, 47]. In flowers, COPT6 is present in sepals, petals, pistil, filaments of stamens, pollen, transmitting tissues of siliques, embryos, and seed envelopment [12, 47] (Figure 2(c)). COPT6 can also be detected in lateral roots, even at low levels, but not in the primary root or at the tip of secondary roots [12] (Figure 2(d)). Whereas aerial COPT6 transcript upregulation by $\mathrm{Cu}$ deficiency is fully dependent on SPL7, its regulation in roots seems to be partially independent of the SPL7 transcription factor [12]. We observed that contrary to COPT1 and COPT2, COPT6 expression is also present under Cu-sufficient conditions [48]. Our analyses of endogenous $\mathrm{Cu}$ levels have shown that the copt6 knock-out lines do not exhibit a significant defect in total $\mathrm{Cu}$ accumulation under either $\mathrm{Cu}$-sufficient or $\mathrm{Cu}$-deficient conditions. However, we observe that copt6 lines display a $\mathrm{Cu}$ distribution defect under low $\mathrm{Cu}$ conditions that leads to increased $\mathrm{Cu}$ levels in rosette leaves and reduced $\mathrm{Cu}$ in seeds [48]. We did not detect $\mathrm{Cu}$ distribution differences when the wild-type COPT6 gene was reintroduced into the copt6 mutant line or under $\mathrm{Cu}$-sufficient conditions [48]. Thus, we conclude that COPT6 protein functions in $\mathrm{Cu}$ redistribution in shoots when $\mathrm{Cu}$ becomes limited, facilitating the transit of $\mathrm{Cu}$ from green tissues to reproductive organs.

\section{The COPT5 Protein Mediates $\mathrm{Cu}$ Mobilization from Storage Sites}

In addition to the COPT proteins involved in cellular $\mathrm{Cu}$ uptake at the plasma membrane, Arabidopsis also possesses COPT family members that function in intracellular $\mathrm{Cu}$ transport. By using Arabidopsis protoplasts, we have localized a functional COPT5-GFP fusion protein to prevacuolar compartments [52, 53]. By using COPT5 promoter fusion to GUS reporter, we determined that COPT5 is expressed mostly in the root vasculature, although it is also present 
at much lower levels in the apical meristems, trichomes, and vascular tissues of hypocotyls, cotyledons, and leaves [53] (Figure 2(d)). In reproductive organs of adult plants, we found COPT5 in pistils, ovules, filament of stamens, silique conducts, and embryos [53] (Figure 2(c)). Unlike the plasma membrane COPT proteins, COPT5 was not present in pollen [53]. Trentmann's group has localized COPT5 to the vacuolar membrane $[52,53]$, and consistently they showed that plant cells lacking a functional COPT5 gene accumulate $\mathrm{Cu}$ in the vacuole [52]. At the systemic level, their copt5 knock-out plants do not show any alteration in total $\mathrm{Cu}$ levels but are defective in interorgan $\mathrm{Cu}$ distribution [52]. Whereas the roots of copt5 mutant seedlings accumulate $\mathrm{Cu}$, siliques and seeds contain less $\mathrm{Cu}$ than wild-type plants [52]. Under severe $\mathrm{Cu}$ deficiency, we observed that copt5 plants exhibit reduced vegetative growth, impaired root elongation, chlorosis, and serious defects in photosynthetic transfer due to reduced plastocyanin accumulation [53] (Figure 2(e)). Despite COPT5 mRNA levels not being altered by environmental $\mathrm{Cu}$ availability, copt5 knock-out plants display major defects upon severe $\mathrm{Cu}$ limitation, suggesting that $\mathrm{Cu}$ levels may somehow regulate the COPT5 function in vacuolar $\mathrm{Cu}$ export either at a posttranscriptional level or through accessory proteins such as vacuolar $\mathrm{Cu}$-reductase $[52,53]$. Therefore, when $\mathrm{Cu}$ is abundant, Arabidopsis plants accumulate excess $\mathrm{Cu}$ in vacuoles, especially in roots. When $\mathrm{Cu}$ is scarce, the COPT5 transporter facilitates $\mathrm{Cu}$ mobilization from storage sites in roots to photosynthetic and reproductive tissues in shoots.

\section{Overexpression of the COPT Proteins Uncovers a Connection between Copper and the Arabidopsis Circadian Clock}

To further characterize COPT function in plants, we obtained Arabidopsis lines that expressed COPT1 and COPT3 genes under the control of the CaMV35S promoter. In both cases, COPT1- and COPT3-overexpressing seedlings accumulated more $\mathrm{Cu}$ than wild-type plants and, as indicated by root length assays, they are more sensitive to high $\mathrm{Cu}$ concentrations in the growth medium [12, 51]. Although overexpression in both yeast and Arabidopsis indicate that the COPT3 protein facilitates $\mathrm{Cu}$ transport, we have not yet deciphered its function in plant $\mathrm{Cu}$ homeostasis [13, 51]. We observed that when COPT-overexpressing plants are grown in soil, their overall size is substantially stunted and they display hyponastic leaves $[48,51]$. The root tips of COPT1-overexpressing seedlings display membrane damage, increased $\mathrm{Ca}^{2+}$ influx and $\mathrm{K}^{+}$efflux, and a drop in the basal peroxide levels, probably due to the $\mathrm{Cu}$-dependent generation of hydroxyl radicals [70]. Interestingly, we showed that the COPT1- and COPT3-overexpressing lines exhibit phenotypes, such as differential flowering time and hypocotyl length, which are not displayed by those plants grown in high $\mathrm{Cu}$ environments but are reminiscent of plants with altered circadian rhythms [51]. We found that the expression of CCA1 and LHY, two MYB transcription factors that participate in the core of the Arabidopsis circadian clock, significantly lowers in COPT1- and COPT3-overexpressing plants, whose survival is compromised in the absence of environmental cycles [51]. Furthermore, addition of $\mathrm{Cu}$ to wild-type plants delays the phase and reduces amplitude, but not the period, of CCA1 and $L H Y$ gene expression oscillations [51]. Taken together, these observations strongly suggest that $\mathrm{Cu}$ influences the Arabidopsis circadian clock [51, 71].

\section{Conclusions and Future Perspectives}

In the last few years, several studies have contributed to our current understanding of the function played by different members of the Arabidopsis COPT family of transporters in plant $\mathrm{Cu}$ homeostasis. We have performed yeast complementation assays, subcellular localization in plant cells, tissue-specific expression patterns, $\mathrm{Cu}$ regulation, and phenotypes associated with copt mutant plants concluding that each COPT transporter has developed specialized functions in plant $\mathrm{Cu}$ homeostasis, especially when $\mathrm{Cu}$ availability is low (Figure 2). For instance, COPT1 mediates root $\mathrm{Cu}$ acquisition, COPT6 facilitates $\mathrm{Cu}$ redistribution in shoots, COPT5 allows $\mathrm{Cu}$ mobilization from storage organelles, and COPT2 functions at the intersection between $\mathrm{Cu}$ and $\mathrm{Fe}$ homeostases. We have observed complex expression patterns and phenotypes associated with various copt mutants indicating that $\mathrm{Cu}$ plays a critical role in reproductive organs. We think that analyses of Arabidopsis plants simultaneously lacking various COPT genes are required to decipher the connection between these transporters and their overall relevance in plant $\mathrm{Cu}$ physiology. Furthermore, identifying the $\mathrm{Cu}$-proteins directly responsible for the phenotypes observed and their biological function will prove to be of enormous help to understand plant $\mathrm{Cu}$ distribution and utilization. Finally, COPT studies have uncovered fascinating connections between $\mathrm{Cu}$ and other processes, including root development, Fe homeostasis, phosphate metabolism, and the circadian clock to be further explored.

\section{Conflict of Interests}

The author declares that there is no conflict of interests regarding the publication of this paper.

\section{Acknowledgments}

The author is grateful to all members of the " $\mathrm{Cu}$ and Fe homeostasis group" at the Department of Biochemistry and Molecular Biology of the University of Valencia for their contribution to the findings described here. The author specially thanks Drs. Lola Peñarrubia and Antoni GarciaMolina for critically reading this paper. The author also apologizes to the colleagues whose relevant work was not cited. Research in our laboratory is currently supported by the AGL2011-29099 grant from the Spanish Ministry of Economy and Competitiveness. 


\section{References}

[1] J. L. Burkhead, K. A. Gogolin Reynolds, S. E. Abdel-Ghany, C. M. Cohu, and M. Pilon, "Copper homeostasis," New Phytologist, vol. 182, no. 4, pp. 799-816, 2009.

[2] S. Puig, N. Andrés-Colás, A. García-Molina, and L. Peñarrubia, "Copper and iron homeostasis in Arabidopsis: responses to metal deficiencies, interactions and biotechnological applications," Plant, Cell and Environment, vol. 30, no. 3, pp. 271-290, 2007.

[3] M. Yuan, S. Wang, Z. Chu, X. Li, and C. Xu, "The bacterial pathogen Xanthomonas oryzae overcomes rice defenses by regulating host copper redistribution," Plant Cell, vol. 22, no. 9, pp. 3164-3176, 2010.

[4] H. Märschner, Mineral Nutrition in Higher Plants, Academic Press, London, UK, 2002.

[5] M. Pilon, C. M. Cohu, K. Ravet, S. E. Abdel-Ghany, and F. Gaymard, "Essential transition metal homeostasis in plants," Current Opinion in Plant Biology, vol. 12, no. 3, pp. 347-357, 2009.

[6] L. Peñarrubia, N. Andrés-Colás, J. Moreno, and S. Puig, "egulation of copper transport in Arabidopsis thaliana: a biochemical oscillator?" Journal of Biological Inorganic Chemistry, vol. 15, no. 1, pp. 29-36, 2010.

[7] K. Ravet and M. Pilon, "Copper and iron homeostasis in plants: the challenges of oxidative stress," Antioxidants and Redox Signaling, vol. 19, no. 9, pp. 919-932, 2013.

[8] J. Kropat, S. Tottey, R. P. Birkenbihl, N. Depège, P. Huijser, and S. Merchant, "A regulator of nutritional copper signaling in Chlamydomonas is an SBP domain protein that recognizes the GTAC core of copper response element," Proceedings of the National Academy of Sciences of the United States of America, vol. 102, no. 51, pp. 18730-18735, 2005.

[9] H. Yamasaki, M. Hayashi, M. Fukazawa, Y. Kobayashi, and T. Shikanai, "SQUAMOSA promoter binding protein-like7 is a central regulator for copper homeostasis in Arabidopsis," Plant Cell, vol. 21, no. 1, pp. 347-361, 2009.

[10] M. Bernal, D. Casero, V. Singh et al., "Transcriptome sequencing identifies SPL7-regulated copper acquisition genes FRO4/FRO5 and the copper dependence of iron homeostasis in Arabidopsis," Plant Cell, vol. 24, no. 2, pp. 738-761, 2012.

[11] R. P. Birkenbihl, G. Jach, H. Saedler, and P. Huijser, "Functional dissection of the plant-specific SBP-domain: overlap of the DNA-binding and nuclear localization domains," Journal of Molecular Biology, vol. 352, no. 3, pp. 585-596, 2005.

[12] H. Jung, S. R. Gayomba, M. A. Rutzke, E. Craft, L. V. Kochian, and O. K. Vatamaniuk, "COPT6 is a plasma membrane transporter that functions in copper homeostasis in Arabidopsis and is a novel target of SQUAMOSA promoter-binding protein-like 7," Journal of Biological Chemistry, vol. 287, no. 40, pp. 3325233267, 2012.

[13] V. Sancenón, S. Puig, H. Mira, D. J. Thiele, and L. Peñarrubia, "Identification of a copper transporter family in Arabidopsis thaliana," Plant Molecular Biology, vol. 51, no. 4, pp. 577-587, 2003.

[14] H. Yamasaki, S. E. Abdel-Ghany, C. M. Cohu, Y. Kobayashi, T. Shikanai, and M. Pilon, "Regulation of copper homeostasis by micro-RNA in Arabidopsis," The Journal of Biological Chemistry, vol. 282, no. 22, pp. 16369-16378, 2007.

[15] R. Sunkar, A. Kapoor, and J. K. Zhu, "Posttranscriptional induction of two $\mathrm{Cu} / \mathrm{Zn}$ superoxide dismutase genes in Arabidopsis is mediated by downregulation of miR398 and important for oxidative stress tolerance," Plant Cell, vol. 18, no. 8, pp. 20512065, 2006.

[16] S. E. Abdel-Ghany and M. Pilon, "MicroRNA-mediated systemic down-regulation of copper protein expression in response to low copper availability in Arabidopsis," Journal of Biological Chemistry, vol. 283, no. 23, pp. 15932-15945, 2008.

[17] S. E. Abdel-Ghany, P. Müller-Moulé, K. K. Niyogi, M. Pilon, and T. Shikanai, "Two P-type ATPases are required for copper delivery in Arabidopsis thaliana chloroplasts," Plant Cell, vol. 17, no. 4, pp. 1233-1251, 2005.

[18] C. M. Cohu and M. Pilon, "Regulation of superoxide dismutase expression by copper availability," Physiologia Plantarum, vol. 129, no. 4, pp. 747-755, 2007.

[19] S. E. Abdel-Ghany, J. L. Burkhead, K. A. Gogolin et al., "AtCCS is a functional homolog of the yeast copper chaperone Ccs1/Lys7," FEBS Letters, vol. 579, no. 11, pp. 2307-2312, 2005.

[20] C. Chu, W. Lee, W. Guo et al., "A copper chaperone for superoxide dismutase that confers three types of copper/zinc superoxide dismutase activity in Arabidopsis," Plant Physiology, vol. 139, no. 1, pp. 425-436, 2005.

[21] C. M. Cohu, S. E. Abdel-Ghany, K. A. Gogolin Reynolds et al., "Copper delivery by the copper chaperone for chloroplast and cytosolic copper/zinc-superoxide dismutases: regulation and unexpected phenotypes in an arabidopsis mutant," Molecular Plant, vol. 2, no. 6, pp. 1336-1350, 2009.

[22] C. Huang, W. Kuo, C. Weiss, and T. Jinn, "Copper chaperonedependent and -independent activation of three copper-zinc superoxide dismutase homologs localized in different cellular compartments in Arabidopsis," Plant Physiology, vol. 158, no. 2, pp. 737-746, 2012.

[23] S. Puig, H. Mira, E. Dorcey et al., "Higher plants possess two different types of ATX1-like copper chaperones," Biochemical and Biophysical Research Communications, vol. 354, no. 2, pp. 385-390, 2007.

[24] H. Mira, F. Martínez-García, and L. Peñarrubia, "Evidence for the plant-specific intercellular transport of the Arabidopsis copper chaperone CCH," Plant Journal, vol. 25, no. 5, pp. 521528, 2001.

[25] T. Hirayama, J. J. Kieber, N. Hirayama et al., "RESPONSIVETO-ANTAGONIST1, a Menkes/Wilson disease-related copper transporter, is required for ethylene signaling in Arabidopsis," Cell, vol. 97, no. 3, pp. 383-393, 1999.

[26] K. E. Woeste and J. J. Kieber, "A strong loss-of-function mutation in RAN1 results in constitutive activation of the ethylene response pathway as well as a rosette-lethal phenotype," Plant Cell, vol. 12, no. 3, pp. 443-455, 2000.

[27] T. Shikanai, P. Müller-Moulé, Y. Munekage, K. K. Niyogi, and M. Pilon, "PAA1, a P-type ATPase of arabidopsis, functions in copper transport in chloroplasts," Plant Cell, vol. 15, no. 6, pp. 1333-1346, 2003.

[28] W. Tapken, K. Ravet, and M. Pilon, "Plastocyanin controls the stabilization of the thylakoid $\mathrm{Cu}$-transporting P-type ATPase PAA2/HMA8 in response to low copper in Arabidopsis," The Journal of Biological Chemistry, vol. 287, no. 22, pp. 18544-18550, 2012.

[29] K. Ravet, F. L. Danford, A. Dihle, M. Pittarello, and M. Pilon, "Spatiotemporal analysis of copper homeostasis in Populus trichocarpa reveals an integrated molecular remodeling for a preferential allocation of copper to plastocyanin in the chloroplasts of developing leaves," Plant Physiology, vol. 157, no. 3, pp. 1300-1312, 2011. 
[30] S. Puig and D. J. Thiele, "Molecular mechanisms of copper uptake and distribution," Current Opinion in Chemical Biology, vol. 6, no. 2, pp. 171-180, 2002.

[31] M. D. Page, J. Kropat, P. P. Hamel, and S. S. Merchant, "Two Chlamydomonas CTR copper transporters with a novel cys-met motif are localized to the plasma membrane and function in copper assimilation," Plant Cell, vol. 21, no. 3, pp. 928-943, 2009.

[32] K. Balamurugan and W. Schaffner, "Copper homeostasis in eukaryotes: teetering on a tightrope," Biochimica et Biophysica Acta: Molecular Cell Research, vol. 1763, no. 7, pp. 737-746, 2006.

[33] T. Nevitt, H. Öhrvik, and D. J. Thiele, "Charting the travels of copper in eukaryotes from yeast to mammals," Biochimica et Biophysica Acta-Molecular Cell Research, vol. 1823, no. 9, pp. 1580-1593, 2012.

[34] C. R. Pope, A. G. Flores, J. H. Kaplan, and V. M. Unger, "Structure and function of copper uptake transporters," Current Topics in Membranes, vol. 69, pp. 97-112, 2012.

[35] C. E. Blaby-Haas and S. S. Merchant, "The ins and outs of algal metal transport," Biochimica et Biophysica Acta, vol. 1823, no. 9 , pp. 1531-1552, 2012.

[36] J. Lee, M. M. O. Peña, Y. Nose, and D. J. Thiele, "Biochemical characterization of the human copper transporter Ctrl," The Journal of Biological Chemistry, vol. 277, no. 6, pp. 4380-4387, 2002.

[37] J. Bertinato, L. Cheung, R. Hoque, and L. J. Plouffe, "Ctr1 transports silver into mammalian cells," Journal of Trace Elements in Medicine and Biology, vol. 24, no. 3, pp. 178-184, 2010.

[38] R. Hassett and D. J. Kosman, "Evidence for $\mathrm{Cu}$ (II) reduction as a component of copper uptake by Saccharomyces cerevisiae," The Journal of Biological Chemistry, vol. 270, no. 1, pp. 128-134, 1995.

[39] E. Georgatsou, L. A. Mavrogiannis, G. S. Fragiadakis, and D. Alexandraki, "The yeast Frelp/Fre2p cupric reductases facilitate copper uptake and are regulated by the copper-modulated Maclp activator," The Journal of Biological Chemistry, vol. 272, no. 21, pp. 13786-13792, 1997.

[40] S. Puig, J. Lee, M. Lau, and D. J. Thiele, "Biochemical and genetic analyses of yeast and human high affinity copper transporters suggest a conserved mechanism for copper uptake," The Journal of Biological Chemistry, vol. 277, no. 29, pp. 26021-26030, 2002.

[41] J. F. Eisses and J. H. Kaplan, "Molecular characterization of hCTR1, the human copper uptake protein.," The Journal of Biological Chemistry, vol. 277, no. 32, pp. 29162-29171, 2002.

[42] A. E. M. Klomp, J. A. Juijn, L. T. M. Van Der Gun, I. E. T. Van Den Berg, R. Berger, and L. W. J. Klomp, "The N-terminus of the human copper transporter 1 (hCTR1) is localized extracellularly, and interacts with itself," Biochemical Journal, vol. 370, part 3, pp. 881-889, 2003.

[43] C. J. de Feo, S. G. Aller, G. S. Siluvai, N. J. Blackburn, and V. M. Unger, "Three-dimensional structure of the human copper transporter hCTR1," Proceedings of the National Academy of Sciences of the United States of America, vol. 106, no. 11, pp. 42374242, 2009.

[44] S. G. Aller and V. M. Unger, "Projection structure of the human copper transporter CTR1 at 6 - $\AA$ resolution reveals a compact trimer with a novel channel-like architecture," Proceedings of the National Academy of Sciences of the United States of America, vol. 103, no. 10, pp. 3627-3632, 2006.

[45] S. G. Aller, E. T. Eng, C. J. De Feo, and V. M. Unger, "Eukaryotic CTR copper uptake transporters require two faces of the third transmembrane domain for helix packing, oligomerization, and function," Journal of Biological Chemistry, vol. 279, no. 51, pp. 53435-53441, 2004.
[46] K. Kampfenkel, S. Kushnir, E. Babiychuk, D. Inze, and M. van Montagu, "Molecular characterization of a putative Arabidopsis thaliana copper transporter and its yeast homologue," The Journal of Biological Chemistry, vol. 270, no. 47, pp. 2847928486, 1995.

[47] A. Perea-Garcia, A. Garcia-Molina, N. Andrés-Colás et al., "Arabidopsis copper transport protein COPT2 participates in the cross talk between iron deficiency responses and lowphosphate signaling," Plant Physiology, vol. 162, no. 1, pp. 180194, 2013.

[48] A. Garcia-Molina, N. Andrés-Colás, A. Perea-García et al., "The arabidopsis COPT6 transport protein functions in copper distribution under copper-deficient conditions," Plant and Cell Physiology, vol. 54, no. 8, pp. 1378-1390, 2013.

[49] S. R. Gayomba, H. Jung, J. Yan et al., "The CTR/COPTdependent copper uptake and SPL7-dependent copper deficiency responses are required for basal cadmium tolerance in A. thaliana," Metallomics, vol. 5, no. 9, pp. 1262-1275, 2013.

[50] E. M. Rees, J. Lee, and D. J. Thiele, "Mobilization of intracellular copper stores by the Ctr2 vacuolar copper transporter," The Journal of Biological Chemistry, vol. 279, no. 52, pp. 5422154229, 2004.

[51] N. Andrés-Colás, A. Perea-García, S. Puig, and L. Peñarrubia, "Deregulated copper transport affects Arabidopsis development especially in the absence of environmental cycles," Plant Physiology, vol. 153, no. 1, pp. 170-184, 2010.

[52] S. Klaumann, S. D. Nickolaus, S. H. Fürst et al., “The tonoplast copper transporter COPT5 acts as an exporter and is required for interorgan allocation of copper in Arabidopsis thaliana," New Phytologist, vol. 192, no. 2, pp. 393-404, 2011.

[53] A. Garcia-Molina, N. Andrés-Colás, A. Perea-García, S. Del Valle-Tascõn, L. Peñarrubia, and S. Puig, "The intracellular arabidopsis COPT5 transport protein is required for photosynthetic electron transport under severe copper deficiency," Plant Journal, vol. 65, no. 6, pp. 848-860, 2011.

[54] V. Sancenón, S. Puig, I. Mateu-Andrés, E. Dorcey, D. J. Thiele, and L. Peñarrubia, "The Arabidopsis copper transporter COPT1 functions in root elongation and pollen development," The Journal of Biological Chemistry, vol. 279, no. 15, pp. 15348-15355, 2004.

[55] H. Wintz, T. Fox, Y. Wu et al., "xpression profiles of Arabidopsis thaliana in mineral deficiencies reveal novel transporters involved in metal homeostasis," The Journal of Biological Chemistry, vol. 278, no. 48, pp. 47644-47653, 2003.

[56] T. del Pozo, V. Cambiazo, and M. González, "Gene expression profiling analysis of copper homeostasis in Arabidopsis thaliana," Biochemical and Biophysical Research Communications, vol. 393, no. 2, pp. 248-252, 2010.

[57] E. P. Colangelo and M. L. Guerinot, "The essential basic helixloop-helix protein FIT1 is required for the iron deficiency response," Plant Cell, vol. 16, no. 12, pp. 3400-3412, 2004.

[58] B. M. Waters, S. A. McInturf, and R. J. Stein, "Rosette iron deficiency transcript and microRNA profiling reveals links between copper and iron homeostasis in Arabidopsis thaliana," Journal of Experimental Botany, vol. 63, no. 16, pp. 5903-5918, 2012.

[59] B. M. Waters and L. C. Armbrust, "Optimal copper supply is required for normal plant iron deficiency responses," Plant Signaling \& Behavior, vol. 8, no. 12, Article ID e26611, 2013.

[60] J. T. Ward, B. Lahner, E. Yakubova, D. E. Salt, and K. G. Raghothama, "The effect of iron on the primary root elongation 
of Arabidopsis during phosphate deficiency," Plant Physiology, vol. 147, no. 3, pp. 1181-1191, 2008.

[61] C. Askwith, D. Eide, A. Van Ho et al., "The FET3 gene of S. cerevisiae encodes a multicopper oxidase required for ferrous iron uptake," Cell, vol. 76, no. 2, pp. 403-410, 1994.

[62] S. La Fontaine, J. M. Quinn, S. S. Nakamoto et al., "Copperdependent iron assimilation pathway in the model photosynthetic eukaryote Chlamydomonas reinhardtii," Eukaryotic Cell, vol. 1, no. 5, pp. 736-757, 2002.

[63] N. E. Hellman and J. D. Gitlin, "Ceruloplasmin metabolism and function," Annual Review of Nutrition, vol. 22, pp. 439-458, 2002.

[64] E. L. Connolly, J. P. Fett, and M. L. Guerinot, "Expression of the IRT1 metal transporter is controlled by metals at the levels of transcript and protein accumulation," Plant Cell, vol. 14, no. 6, pp. 1347-1357, 2002.

[65] R. Henriques, J. Jásik, M. Klein et al., "Knock-out of Arabidopsis metal transporter gene IRT1 results in iron deficiency accompanied by cell differentiation defects," Plant Molecular Biology, vol. 50, no. 4-5, pp. 587-597, 2002.

[66] C. Varotto, D. Maiwald, P. Pesaresi, P. Jahns, F. Salamini, and D. Leister, "The metal ion transporter IRT1 is necessary for iron homeostasis and efficient photosynthesis in Arabidopsis thaliana," Plant Journal, vol. 31, no. 5, pp. 589-599, 2002.

[67] G. Vert, N. Grotz, F. Dédaldéchamp et al., "IRT1, an Arabidopsis transporter essential for iron uptake from the soil and for plant growth," Plant Cell, vol. 14, no. 6, pp. 1223-1233, 2002.

[68] S. Svistoonoff, A. Creff, M. Reymond et al., "Root tip contact with low-phosphate media reprograms plant root architecture," Nature Genetics, vol. 39, no. 6, pp. 792-796, 2007.

[69] M. Thibaud, J. Arrighi, V. Bayle et al., "Dissection of local and systemic transcriptional responses to phosphate starvation in Arabidopsis," Plant Journal, vol. 64, no. 5, pp. 775-789, 2010.

[70] A. Rodrigo-Moreno, N. Andrés-Colás, C. Poschenrieder, B. Gunsé, L. Peñarrubia, and S. Shabala, "Calcium- and potassium-permeable plasma membrane transporters are activated by copper in Arabidopsis root tips: linking copper transport with cytosolic hydroxyl radical production," Plant, Cell and Environment, vol. 36, no. 4, pp. 844-855, 2013.

[71] A. Perea-Garcia, N. Andres-Colas, and L. Peñarrubia, "Copper homeostasis influences the circadian clock in Arabidopsis," Plant Signaling \& Behavior, vol. 5, no. 10, pp. 1237-1240, 2010. 

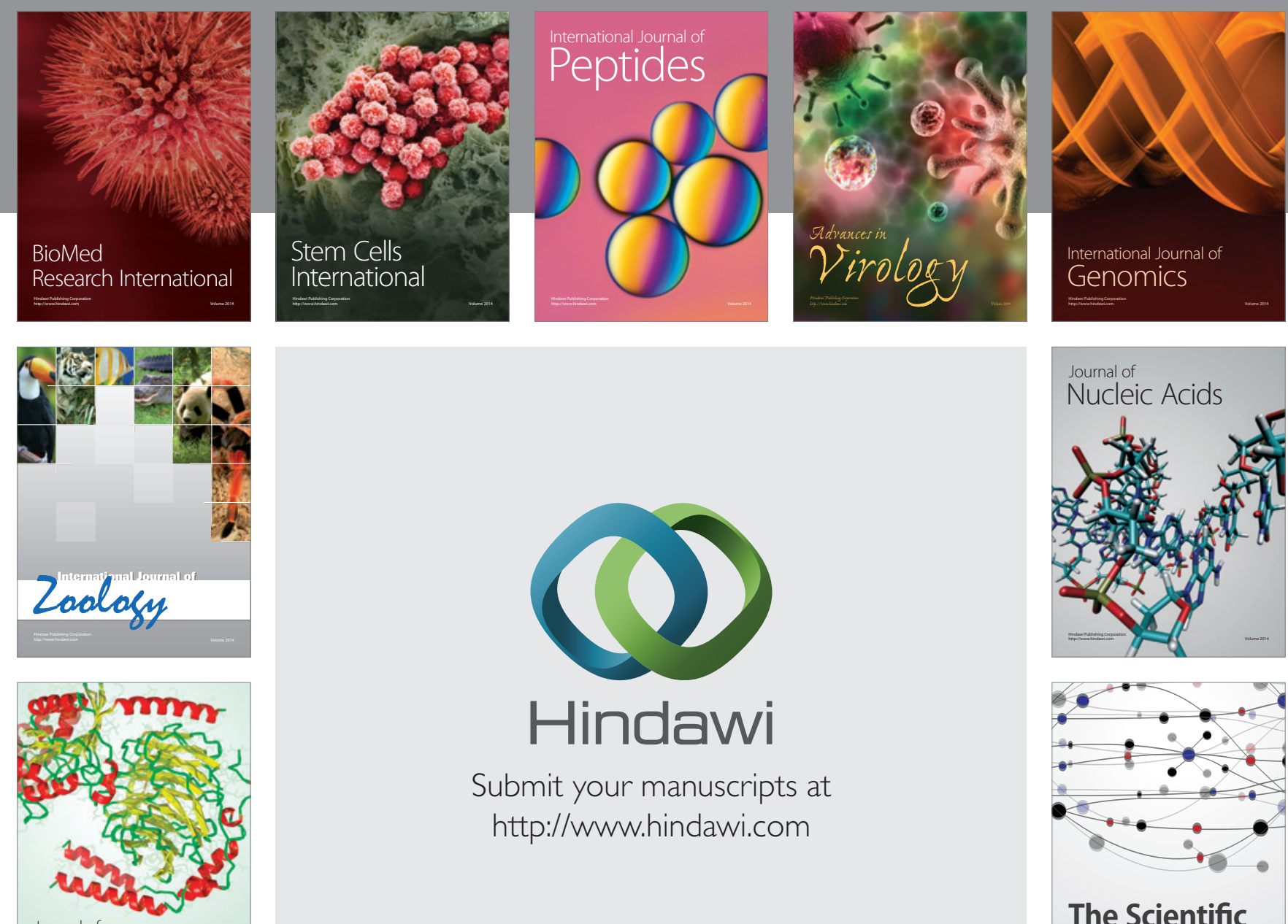

Submit your manuscripts at

http://www.hindawi.com

Journal of
Signal Transduction
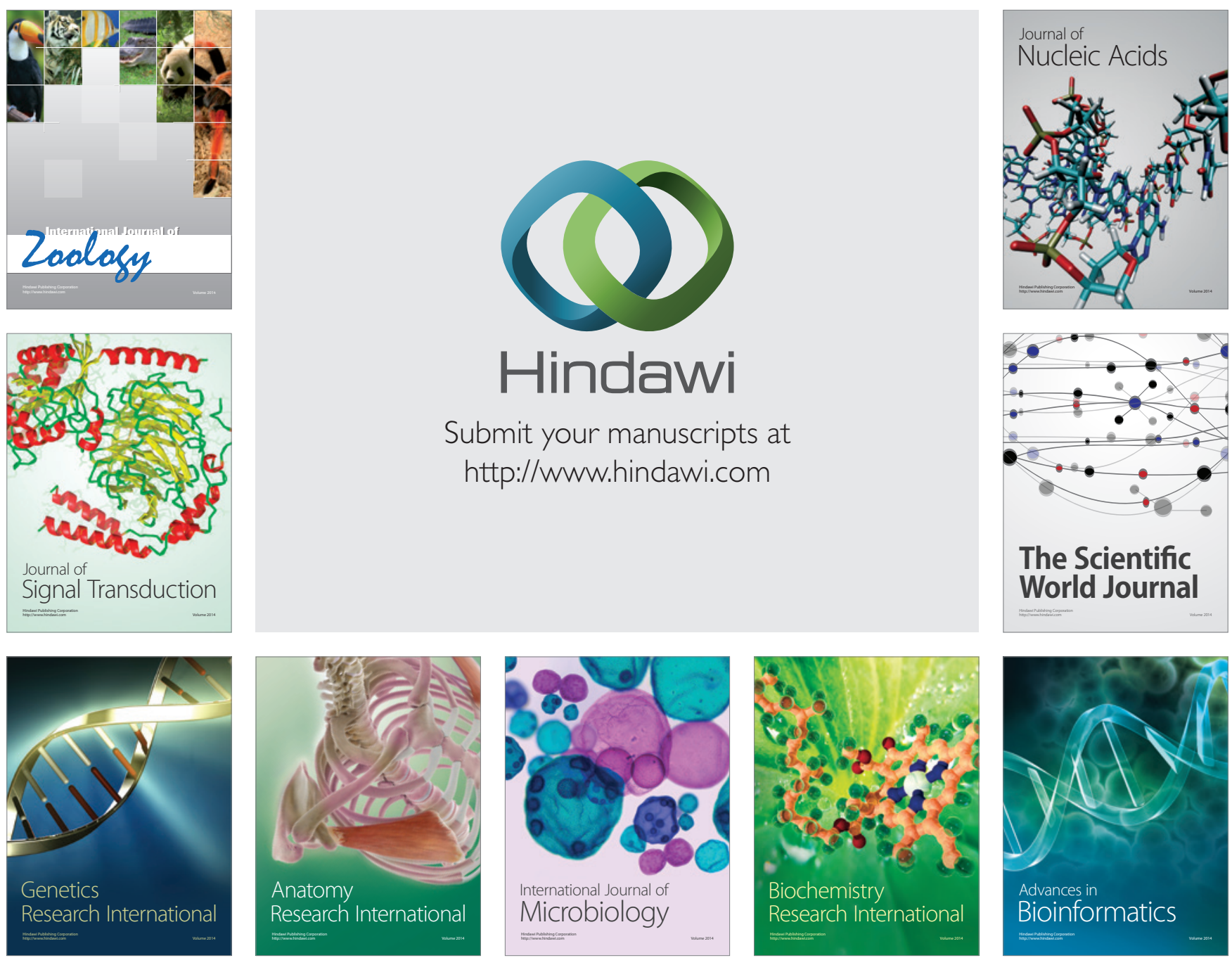

The Scientific World Journal
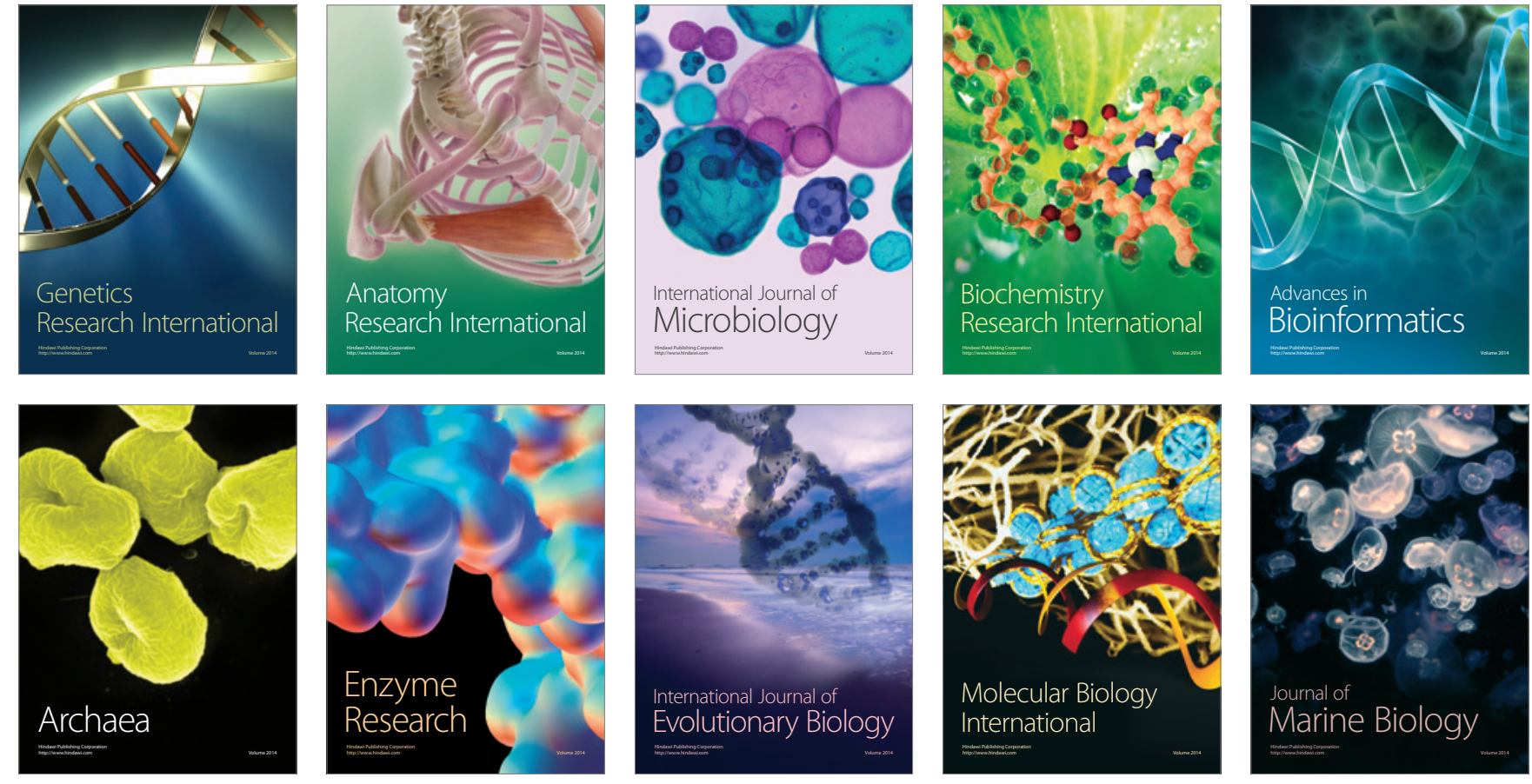